Social Work/Maatskaplike Werk Vol 56 No 2; Issue 7

http://socialwork.journals.ac.za/pub

doi:http://dx.doi.org/10.15270/56-2-821

THE ROLE OF TRADITIONAL LEADERSHIP IN SUPPORTING ORPHANS AND VULNERABLE CHILDREN IN ZIMBABWE: AFRICAN TRADITIONAL LEADERSHIP PERSPECTIVE

John Ringson

The experiences of orphans and vulnerable children (OVC) in Zimbabwe find expression in the maxim that says 'Where two elephants fight, the grass suffers the most'. Orphans and vulnerable children in Zimbabwe have been the casualties of disharmony between traditional and contemporary leadership philosophies for more than three decades. Using a phenomenological approach, the study involved 20 key informants, who included community leaders and OVC caregivers. Underpinned by the traditional leadership perspectives, the study examined the role of traditional leaders in supporting OVC for the purposes of integrating its relevant compatible elements with modern OVC care and support systems. The study showed that there is lack of synchronicity between traditional and contemporary OVC care and support systems, which ultimately compromises the effectiveness of the social care professions in rural communities in Zimbabwe. The study recommends the establishment of an integrated contextually-based OVC care and support model to enhance the relationship between traditional and contemporary leadership in Zimbabwe.

Dr John Ringson, Postdoctoral Research Fellow, University of Johannesburg, Faculty of Humanities, Department of Social Work, Kingsway Campus, Auckland Park, Johannesburg, South Africa.

jringson@gmail.com

Keywords: traditional leadership, leadership perspective, leadership philosopies, phenomenological, orphans and vulnerable children, Zimbabwe 



\section{THE ROLE OF TRADITIONAL LEADERSHIP IN SUPPORTING ORPHANS AND VULNERABLE CHILDREN IN ZIMBABWE: AFRICAN TRADITIONAL LEADERSHIP PERSPECTIVE}

\section{John Ringson}

Dr John Ringson, Postdoctoral Research Fellow, University of Johannesburg, Faculty of Humanities, Department of Social Work, Kingsway Campus, Auckland Park, Johannesburg, South Africa.

\section{INTRODUCTION}

The Zimbabwean government has adopted a new constitution which recognises the role of the institution of traditional leadership, which operates alongside the modern state structures (Chigwata, 2016:1).The current constitution of Zimbabwe clearly stipulates that it is there to strengthen, regulate and enforce the status and roles of traditional leadership within their area of jurisdiction (Constitution of Zimbabwe, 2013), Despite this upliftment and strict regulation, the role and relevance of the institutions of traditional leadership regarding orphans and vulnerable children have been largely compromised in Zimbabwe. Broodryk (2004) argued that traditional and modern state leadership structures are often in conflict, largely because of competing claims to resources, power and legitimacy. Masuka, Banda and Mabvurira (2012) assert that the inception of modern leadership strategies such as human rights approaches, policy and legislative frameworks seriously contradicted and undermined some traditional leadership tendencies. These traditional leadership tendencies which were condemned included human rights abuses, child labour and a dictatorial approach. In spite these weaknesses of traditional leadership, the World Bank (WB) (2000) insisted that it should be acknowledged for embracing grassroots participation and giving people opportunities to shape their own destiny, compared to the top-down approaches which do not involve people at the grassroots level.

This study therefore examines prevailing traditional leadership roles in OVC care and support with a view to integrating those elements that are compatible with the contemporary leadership roles in local rural tribal communities of Zimbabwe. The study also examines how the traditional leadership roles affect the services of the social work profession and social development within the rural communities of Zimbabwe. Whilst there are commendable aspects of the traditional leadership approaches to OVC care and support and the contemporary systems, the disjuncture between them has caused problems. The main research question of this study is consequently: How can the traditional and contemporary leadership roles in OVC care and support be integrated for the sustainable livelihood of OVC in Zimbabwe? The two main objectives of the study were as follows: (i) to examine the relevance of the roles of traditional leadership in OVC care and support within the rural communities of Zimbabwe, and (ii) to assess the implications of traditional leadership roles in OVC care and support in the social work profession and social development in Zimbabwe.

This study accordingly used the traditional leadership perspective as a lens to examine the relevance of the roles of traditional leadership in OVC care and support and how it affects the social work profession and the OVCs within the rural communities of Zimbabwe. The study first presents the context and perspective of African traditional leadership in OVC care and support in Zimbabwe. This is followed by the methodology, presentation and discussion of the findings. In conclusion, the recommendations and the implications of the study for social work and social development are presented.

\section{AFRICAN TRADITIONAL LEADERSHIP PERSPECTIVE}

Throughout the history of African traditional leadership, the welfare of people was centred on traditional governance carried out by traditional leaders within the parameters of their leadership styles (Ayittey, 2006). However, the African traditional leadership approach was diluted through 
colonialism, which imposed Western models of leadership. The studies carried out by Mararike (2004), Machingura (2012) and Chigwata (2016) show that traditional coping mechanisms among the vulnerable in the pre-colonial era in Zimbabwe were managed the Shona tribal chiefs. Bourdillion (1990) and Chigwata (2016) also indicate that before colonialism the chief's domain was called nyika (country) and was comprised of the household (imba), village (raini or ruwa) and community (dunhu). According to Gyekye (1997), before colonialism, chiefs were the sole rulers over their areas of jurisdiction, and the community was a combination of many households and villages under the chief's domain. It was within this domain that the Shona chiefs had the power to ensure that their subjects and the disadvantaged groups in their communities were well fed and lived in peace and tranquillity.

According to Bourdillion (1990), the traditional African chiefs performed many functions within their areas of jurisdiction. Bourdillion (1990) posits that the roles of the Shona chiefs had both socioeconomic and political dimensions. The chiefs were to provide for all the fundamental human needs of the people within their jurisdictions. These basic human needs included physiological and psychological needs; attempts to address these needs led to the development of human rights through international conventions such as the Universal Declaration of Human Rights (UNDHR) of 1948, the Convention on the Elimination of all Forms of Discrimination against Women (CEDAW) of 1981 and the United Nations Convention on the Rights of the Child (UNCRC) of 1989 (Roby, 2011). Thus, in the simplest terms, it can be argued that even in the pre-colonial era, when rights-based models were not yet in place, the chiefs were already administrators of human rights in their traditional support mechanisms. The main difference between the traditional and contemporary leadership methods of executing these roles was that the former used the closed systems leadership approach while the later used an open systems leadership approach. Ayittey (2006) notes that traditional African society had all four units of the government: the chief, an inner council, a council of elders and a village assembly, which also replicates contemporary government structures.

Machingura (2012) asserts that, traditionally, the Shona chiefs in Zimbabwe were responsible for the administration and maintenance of good order. The concept of administration in its broadest sense suggests that the roles of the chiefs covered various dimensions of human life. In this context, an administrator could be both a governor and leader. This concurs with the views of Banana (1995) and Ayittey (2006), who argued that in the pre-colonial era African chiefs were influential and respectable figures in the communities, and more highly respected than in the post-independence era. The chiefs were also religious leaders and heads of their tribes. As religious leaders, according to Machingura (2012:181), they were presumed to be the direct and living representatives of the ancestral spirits, which meant their duty was to "pay homage to or placate ancestral spirits by rituals, sacrifices and offerings to obtain their fortunes and blessings in the land". This religious responsibility of the Shona chiefs was very important in their communities because it fostered the sense of unity and communality of the people. Thus, Shona chiefs were conduits of the spirit of ubuntu/unhu through their religious and administrative positions.

Furthermore, the Shona chiefs were mediators between the people and their ancestors. Gelfand (1997) emphasized that chiefs would plead with the ancestors not to punish the community with pests, floods, droughts, sickness or hunger. There was a common belief that where there is bad blood between the ancestors and the people, according to Ayittey (2006), the ancestral spirits would blight the earth and withhold fertility, inflict illness upon the living, cause deaths and generally place human life in peril. In a similar vein Machingura (2012:403) notes that 'a chief was a sacred man in the Shona communities and insulting a chief was a taboo in Shona communities and would invite calamities and misfortunes to the community'. Matshabaphala (2017) argues that authoritarianism within some of the African leaders is an aspect of the sacredness attached to their appointment as leaders. Banana (1995) points out that when a community respects their chief, the ancestral spirits show their pleasure by granting them plentiful fruit, rain and harvests. Machingura (2012) argues that life and the divine election of the chiefs was measured by their ability to bring order, justice and peace in their chiefdom. In modern societies, where there are socio-economic injustices, incurable diseases, conflict or blood 
wars and hunger, traditional leaders attribute such challenges to the lack of divine electiveness and the disapproval of leadership by the ancestors.

It was also within the Shona chiefs' responsibilities to empower their communities. Mararike (2014) and Ayittey (1991) concur that chiefs would freely give cattle and allocate land to the needy. Land and cattle were critical assets in ubuntu/unhu traditions and African rural tribal communities; their wealth and generosity to the poor revolved around these elements of the economy. Mararike (2004) points out that in ubuntu/unhu philosophy, a child would be celebrated and honoured when he buys cattle, owns a piece of land and builds a house. This also shows that the Shona chiefs were involved in providing for all the human needs. Thus, in performing their roles, the chiefs would use the traditional strategies such as Zunde raMambo (King's granary), the extended family and the inheritance of the deceased brother or uncle's wife and children to support the OVC in their communities and families.

Teffo (1994) asserts that in traditional communities, the existence of humans was explained in the context of socialization. People could only exist in concert with others. This is the underlying tenet of ubuntu/unhu, umuntu ngumuntu ngabantu or munhu munhu nevanhu in Zulu and Shona respectively, which translates as a person is a person through other people. This understanding of community mutualism is expressed through group solidarity in terms of the 'collective fingers theory' of social consensus which states: a man is a man only through others, and I am because we are (Mosana, 2002:33). Mosana further emphasizes that the collective fingers theory envisages that one must encounter the "we" before the "I'. This model of thinking has the potential of recalibrating the contemporary governance systems and consolidating various ethnic and socio-cultural formations within the context of OVC care and support.

An example of such traditional social structures is communal interdependence, which is an embodiment of co-operative community farming (nhimbe), Zunde raMambo and cooperative cattle herding (majana), extended family and traditional African courts. The concept of co-operative community farming means that two or more families would come together and combine their resources for ploughing, cultivating, weeding and/or harvesting each other's field (Mararike, 2004). In doing so, the OVC and other disadvantaged people were direct beneficiaries of these socio-economic activities spearheaded by traditional leaders within their communities. According to Machingura (2012) and Ringson (2017), the Shona term Zunde raMambo is conceptualised as a method of growing and storing grain for use when food supplies are either high or low. He further emphasizes that it was a traditional practice associated with the feeding abilities of the Shona and the Ndebele kings and chiefs in Zimbabwe.

Similarly, Mararike (2014) observes that co-operative cattle herding was a tradition whereby families would come together and agree to a roster for herding each other's cattle. In this view, such traditional structures promoted philanthropic approaches that catered for the disadvantaged and the underprivileged individuals of society, including OVC. Letseka (2012) argues that there is a direct link between contemporary Western models of OVC care and support and the traditional models that can be easily integrated. However, the mismatch between the two lies in the fact that the African-oriented models are based on a mutual communitarian approach, whereas the Western-oriented models tend to be capitalistic, individualistic and competitive. The two leadership perspectives that differentiate the traditional leadership and contemporary leadership ways of executing their roles can be described in terms of the closed- and open-systems approaches.

In this context, OVC care and support involves the provision of the physical, psychological, spiritual and the emotional needs of individuals' lives. Max-Neef (1993) argues that leadership plays a significant role in creating an environment conducive to social work practitioners being able to execute their professional services. Thus, if there are leadership wrangles, as in the context of Zimbabwe where there is a leadership imbalance between the traditional closed and the contemporary open approaches, it makes the environment difficult for social profession to provide its services. In a study conducted by Ringson (2017) on community-based coping strategies on OVC in Zimbabwe, it was discovered that 
after 2000, the licences of most of the social work service providers, especially the international organizations, were terminated because of their perceived meddling in the politics of the country and their failure to uphold some traditional leadership protocols and etiquette. As a result, most of the OVCs and their caregivers were exposed to a lot of hardships and challenges, especially within the rural communities and other marginalized places.

\section{CONCEPTUALIZING ORPHANS AND VULNERABLE CHILDREN AND CAREGIVERS}

The concept of OVC is a combination of two principal terms: 'orphan' and 'vulnerable children'. Both terms are too complex to be have a universally understood meaning, and hence people conceptualize them contextually. For instance, an 'orphan' or 'vulnerable child' may mean one thing to policy makers and another thing to the service providers. German (2005) postulates that to draw the most appropriate meaning out of these two main concepts, they should be conceptualized separately and subsequently combined as a single concept. Thus, a child was conceptualised first, followed by 'orphan' and then the term 'vulnerable children' and finally a combined concept 'orphans and vulnerable children'. There is some tension in the definition of the term 'child' in the traditional and legal understanding. This misunderstanding, as argued by the studies carried out by Hodgson (2009) and Shanalingigwa (2009), created a tension between modern and traditional approaches in child-rearing. The Child Protection and Adoption Act of 1997 (Chapter 5.06) defines a child as anyone below the age of 18 (Government of Zimbabwe, 2013). The challenge comes in reconciling this with legislation such as the Marriage Act (Chapter 5.11), which stipulates the minimum age of marriage to be 18 years for boys and 16 years for girls. This may be interpreted as implying a contradiction, as it defines children as those 18 years and below, but when it comes to marriage girls are regarded as adults at 16 .

Furthermore, the Criminal Procedure and Evidence Act permits sexual relations between an adult man and a girl of 16 years. To make matters worse, the Customary Marriages Act (Chapter 5.07) of Zimbabwe does not provide for minimum age of marriage (GoZ, 2013). The Marriage Act also gives powers and authority to the parents to give consent to the marriage of their girl child under the age of 18. Thus, whilst the contemporary legal definitions interpret a child as anyone below the age 18, there is are legal discrepancies in relation to the Marriage Act (Chapter 5.11), the Criminal Procedure and Evidence Act and the Customary Marriages Act (Chapter 5.07).

Contextually, there are two parallel dimensions of the conceptualization of the OVC in Zimbabwe, namely the legal and cultural understanding of OVC. The legal understanding follows the universal conceptualization as posited by Lumbi (2007) that an 'orphan' is a child under the age of 18 who lost both or one of his/her biological parents, while vulnerable children are children under the age of 18 who might have both parents but are subjected to abject poverty or living with disability, forced marriages, street kids and abandoned. The cultural or traditional understanding of an 'orphan' in Zimbabwe has no specified age limit; as long as a child has lost both or one of his or her parents, they still deserve care and support (Chizororo, 2008). This also applies to 'vulnerable' children, where the focuses is on the problems affecting the children. A recent empirical study carried out by Ringson (2019) in Zimbabwe on cultural contestation of child rights, it was discovered that smooth OVC care and support of children in rural communities is hindered due to the conflicts emanating from the two main opposing conceptualization of orphans and vulnerable children which are the right based legal definition and the traditional understanding.

The conceptualization discord between the legal contemporary definition of OVC and the culturaltraditional definition impedes in the smooth execution of the social work practitioners within the rural communities of Zimbabwe. As a matter of clarity, the way traditional leaders understands OVCs determines the way they expect them to be treated by the social practitioners. Mugumbate and Chereni (2019) posit that the social work profession needs to be contextually blended with the cultural and traditional beliefs of the local communities, especially those which are still to be transformed into modern-contemporary societies. Thus, in an attempt to create harmony between the contemporary and 
traditional approaches to OVC care and support, the government enacted a broad-based National Action Plan for Orphans and Vulnerable Children (NAP for OVC) in 2004 to integrate the indigenous knowledge of traditional leadership with the contemporary approaches in OVC care and support. However, on the contrary, Ringson (2019) argues that, instead of seeking a smooth engagement between the two, the local rural communities should continue to espouse their traditional ways of OVC care and support.

Care-giving, according to Ringson (2019), is a hybridized compound word meaning caring and support. In the context of this study, a care-giver refers to the extended family members, single mothers or fathers who are taking care of the orphans of their deceased relatives or well-wishers within the community who are voluntarily or by law taking care of OVCs. Chizororo (2008) posits that within the African traditional approach of OVC care and support, it is the right of an OVC to be absorbed by the immediate family if his/her parents are deceased, or if his/her parents are living in abject poverty, chronically or disabled. Thus, in context of this study care-givers refers to the grandmothers/fathers, aunts/uncles and brothers/sisters who are offering primary care and support to OVCs, specifically within the Gutu District of Zimbabwe.

\section{METHODOLOGY}

The study was a qualitative phenomenological study (Hewlett, 2013; Merriam, 2009). Merriam (2009:25) posited that phenomenology is a study of people's conscious experience of their lifeworld, that is their everyday life and social actions. This study sought to establish the perceptions, views, experiences and feelings of the community leaders and OVC caregivers regarding the roles and efficacy of traditional leadership in supporting OVC in Zimbabwe. Two populations were identified in this study: (i) 10 community leaders consisting of traditional leaders, faith-based organization representatives, non-governmental organization representatives and government line ministries that deal with OVC, and (ii) 10 OVC caregivers in the Gutu District of Zimbabwe. Purposive sampling was used to select the 10 community leaders and the 10 care-givers who were either working or living in the Gutu District of Zimbabwe. The criteria for choosing the first sample was that they were traditional leaders, faith-based organization leader, non-governmental organization leader and government line ministry officer working and residing in Gutu District of Zimbabwe. The role of the community leaders in OVC care and support is to create an environment conducive to the stakeholders being able to perform their services. For instance, the government community leaders' role is in policy formulation and coordinating the implementation of those policies in OVC care and support. The NGOs and religious community leaders' roles are mainly charitable and philanthropic in nature. Their involvement in OVC care and support is in implementing the government welfare policies in OVC care and support. The traditional community leaders' role in OVC care and support is that they are the traditional and cultural stewards of the OVCs within their jurisdiction. Their roles replicate those of the government community leaders, with the differences being that the traditional leaders' roles are culturally oriented towards traditional values, while those of the government leaders are contemporary and modern. The reason why the community leaders were purposively selected from the different groups was based on the different leadership roles they play in OVC care and support in Zimbabwe. Thus, their direct and indirect involvement in OVC care and support through their leadership roles purposively qualified them as potentially information-rich sources for this study.

The other criteria for selecting the OVC care-givers was that they were involved in OVC care and support and residing in the Gutu District of Zimbabwe. The roles of the caregivers in OVC care and support include all the dimensions of psychosocial support such as education, medication, provision of food, counselling, provision of shelter and clothing, to mention but a few. In fact, the caregivers are the ones who offer primary care and support on a daily basis to the OVC and their roles are more direct than the roles played by the contemporary and traditional leadership in OVC care and support in Zimbabwe. As such, the caregivers were purposively selected to furnish this study with their perceptions, views and opinions in the roles of traditional leadership in OVC care and support in 
Zimbabwe. All the participants selected, including the community leaders, were aged 18 years and above and they were deliberately selected on the basis that they had appropriate relevant information to respond to the research questions and advance objectives of this study.

Data were collected through in-depth interviews. The people who are part of the community have well established pre-existing networks that allow them to participate without fear of disclosing sensitive information (Bloor, Frankland, Thomas, Robson, 2001). Relevant questions put to the community leaders included: Within your jurisdiction as a traditional/community leader, what roles do perform for supporting OVCs in Gutu District of Zimbabwe? Is your working relationship with other stakeholders in harmony? The OVC caregivers were mainly interviewed on the effectiveness and working relationship between the traditional leaders and contemporary leaders in OVC care and support within their communities. Data were collected in a Shona language and then translated into English.

The data were analysed using the model of thematic analysis suggested by Braun and Clarke (2006). Braun and Clarke argue that thematic analysis provides an accessible open-coding approach to analysing qualitative data. This involved familiarizing myself with the data, reviewing and defining themes. As such, an inductive method of theme development was undertaken on the basis of the content of the data. Codes were used to differentiate and identify the data sources. The community leadership participants were coded as P1 to P10 and the caregivers were coded as CG1 to CG10. The trustworthiness (Lincoln \& Guba, 1985) of the study was enhanced by triangulation of sites and sources, using purposive sampling and providing a detailed description of the methods used. Since the study involved human participants, pertinent ethical issues were considered prior to and during the study. Ethical approval was obtained from the relevant ethical department, namely the Research Council of Zimbabwe (RCZ). Written informed consent was obtained from all the participants before the study was undertaken. Lastly, questions in the study tools were focused on the topic and, as far as possible, nothing outside the scope of the study was discussed.

\section{FINDINGS}

\section{Disharmony between traditional and modern leadership structures}

Disharmony between traditional and modern leadership structures was one of the recurring themes from the community leadership participants. The findings showed that the dual governance systems adopted by Zimbabwe are always in conflict. The contemporary structures always subvert the traditional leadership in breach of the autonomous powers vested in them by the Constitution of the country. This was directly confirmed by P1, P2, P3, P4, P5 and P6 who attested that the stakeholders' relationships in OVC care and support are not compatible and this is mainly because of the disunity of the two parallel governance systems. In this view, P1 a traditional leader stated that as chiefs and headmen their roles were reduced to be custodians of culture and traditions within their communities and the rest has been taken over by the government. When further probed as what exactly caused this to happen, the respondents revealed that the drastic increase of population, urbanization, colonialism and modern leadership approaches led to this happening. Emphasising his role in OVC care and support as a traditional leader, $\mathrm{P} 1$ remarked:

As a headman, I carry out delegated duties within my area of jurisdiction from the paramount chief and report back the outcomes. Using my discretion, I also recommend OVC in my area to be registered for birth certificates if the relatives are not available to give enough testimonials about their identity.

In corroboration of the above, P2 and P6, both government officials but from different ministries, concurred that traditional leaders' roles these days are predominantly to administer the ritual ceremonies associated with rainfall and plead with ancestors or God in times of misfortune such as drought, disease and death in communities. These government officials indicated that some of these tasks the modern government cannot do and hence the traditional leaders are given the freedom to preside over them. It was interesting to note that the traditional leaders are blaming the modern 
government for the socio-economic ills facing the communities and the country at large. Responding to this, traditional leaders argued that the prevalence of HIV/AIDS that killed mostly economically active people and leaving behind OVCs is a result of a curse sent by God and the ancestors. This problem is said to have been aggravated by not adhering to the traditions and cultural values enshrined in the leadership roles of traditional leaders. P2 said:

In our culture, we don't believe that HIV/AIDS, droughts and deaths come when we are in right standing with our ancestors and God. These are caused by this generation's abandonment of our culture and traditions. We used to brew beer and do rituals for our ancestors to thank them for the harvest and asking them for the rains and fortunes for our children, but all these now have been buried in the dustbin of dead history.

Similarly, P3 indicated that, as the co-ordinating government arm of all charity work at community level, their ministry is obliged to work with the traditional leaders and incorporate their programmes into other work. In his view, the main hindrance to this relationship lies in politically motivated conflicts between traditional and contemporary leadership. In theory, traditional leadership is being venerated but in practice it is the contemporary leadership system that is in control of everything. The councillors and the members of parliament have subverted the operation of traditional leadership at grassroots level. Traditional welfare strategies such as the Zunde raMambo are practically owned by the government, whilst in theory they are owned by traditional leaders. The findings also showed that the extended family networks, child inheritance and other traditional inheritance approaches that were meant to support the OVC have been subverted under the pretext that they were human rights abuses and child exploitation. The findings also indicated that the traditional leaders are now government workers and tend to operate as civil servants, which was not previously the case. When further interrogated P3 commented on one of the traditional welfare strategies for OVC:

The Zunde raMambo concept from a traditional understanding is no longer in existence. But I can subscribe to the idea that it has evolved and developed into modern concepts such as NGOs and social welfare programmes. The reason for this is the traditional Zunde was agrarian oriented before industry and technology developed to its current state. Rainfall is becoming erratic due to climatic changes and droughts are regularly experienced.

The other view, which was strongly emphasised by the traditional leaders P4 and P5, was that traditional roles and activities today are now owned by the government since traditional leadership has been subsumed under and merged into the government structures for political convenience. The findings indicated that the chiefs' power is not independent from that of government, since the government confirms that traditional leaders and hence traditional leadership are an extension of the government. P5 explained:

The traditional leaders and the government are no longer parallel governments as it was formerly portrayed. It is a theory to say that but practically chiefs and the contemporary government is now one thing. This is evidenced by the inclusion of chiefs in parliament representing the incumbent government.

In addition, P6, a non-governmental organization representative, indicated that the traditional leaders in Zimbabwe has been relieved of their administrative mandate and are now mainly active as cultural custodians of their rural local communities. Thus they find that their hands are tied when it comes to implementing their responsibilities. P6 remarked:

The modern governance structures have eroded all the administrative duties and responsibilities of the traditional leaders. The traditional leaders are no longer having their political and governance powers they used to have before colonialism. In Zimbabwe, chiefs have been reduced to the level of civil servants and government employees.

Similarly, P7, a representative of councillors in Gutu District, notes that whilst there is a plethora of responsibilities that the traditional leaders ought to carry out independently, their roles and leadership 
functions are manifesting through contemporary leadership practices. He indicated that at the practical level traditional leaders in Zimbabwe are a grassroots leadership arm of the government and as such a parallel government regulated by the Traditional Leadership Act. In this regard, one of the government community leader, P8, asserted that the main contested factors that aggravate the working relationship between traditional and contemporary leadership have to do with issues of accountability and transparency. P9 and P10, a faith-based organization leader and District Aids coordinator, indicated that the introduction of the modern principles of good governance, which condemn authoritarianism, child labour and some marriage ceremonies and rituals, have forced the traditional leaders to adjust to contemporary approaches or a back seat in OVC care and support. However, when asked about the solution, most of the community leaders indicated that there is need for contemporary leaders to respect the roles of traditional leaders and integrate their efforts for the sustainable livelihood of OVC in their communities.

\section{LACK OF RESOURCES AND POLITICAL DIFFERENCES}

In corroboration of the community leadership's views, the caregivers of OVCs gave their views on the efficacy of traditional leadership in OVC care and support in the Gutu District of Zimbabwe. Most of the caregivers indicated that the traditional leaders are doing something constructive, but their efforts are constantly compromised by the stakeholders' poor relationships as a result of political sensitivities and differences in Zimbabwe. The caregivers also indicated that the lack of resources is the greatest hindrance to the effective implementation of the roles of traditional leadership. Thus, the lack of resources and political differences among the stakeholders were among the major recurring themes to corroborate the views of community leaders. While the care-giver participants, who include CG1, CG2, CG4, CG6, were outspoken in expressing this view. CG1 remarked:

Traditional leaders in our community are trying their best to help us in as far as land allocation and helping the non-governmental organisations to identify the OVC who need assistance within their areas of jurisdiction. The major problem that our traditional leadership has is that they don't have resources to directly help their people. All the important resources are owned by the government and they can only access them through the government, which is not an easy process.

In support of this view, CG2 also indicated that traditional leaders do not have the resources to help people. She further said that long ago chiefs were known be rich and well-to-do people in the community, which is different with communities today, where chiefs want to be fed by the people whom they are leading. She said:

As you can see that our rural communities depend on farming and we have been receiving erratic rains for the past 10 years. Chiefs used to assist OVC from their harvest and livestock through their Zunde raMambo scheme. Whilst their roles are well articulated on paper but practically, they don't have resources to implement their roles. Most of our traditional leaders have spoiled their relationships with the government and non-governmental organisations on political reasons.

The care-givers participants also indicated that political differences among the stakeholders has paralysed the roles of traditional leaders within the tribal rural communities of Zimbabwe. It was also mentioned that political differences among the stakeholders has crippled not only the traditional roles but the whole delivery system expected from both contemporary and traditional leadership. CG3 remarked:

Ever since our traditional leaders were grabbed and put in the ambit of the contemporary leadership, they were made to represent the incumbent government and grassroots level. Recently, the incumbent political party terminated the contracts of international organizations that were helping OVC using these traditional leaders accusing them to be regime change agents from western countries. These political misunderstanding has divided 
the tribal rural communities to the extent that even the chiefs are no longer trusted with their subjects.

The care-givers pointed out that human rights abuses emanated from political violence in Zimbabwe which was mainly alleged to have been caused by traditional leaders who were being used by the main political party to persecute people they suspected to be in the opposition parties. This view was corroborated by CG5:

The main problem with our traditional leaders is that they have lost trust and respect from their subjects because they are always manipulated with the main political party to unleash political violence in their communities. For example, in our area, chiefs and headmen were forcing people to vote for Zanu-PF and failure to do that they were beaten, and their houses burnt. Some of these chiefs are now involved in corruptions in their endeavour to adhere to the politics of patronage. This has reduced the integrity of the traditional leaders in our rural tribal communities.

The participants also cited the politics of succession in the incumbent government over the last decade as dealing a major blow to the service delivery of OVC care by both the contemporary leaders as well as the traditional leaders. CG7 claimed:

Succession politics in both the incumbent political party and government in Zimbabwe have shifted the key stakeholders in OVC care and support in Zimbabwe into political battles. This has divided the communities and all the development programmes that were originally meant for the traditional leaders have been hijacked by the incumbent political leaders.

To this end, care-givers predominantly agreed that the traditional leaders had done a lot in the past to help the OVC in their communities, but today because of the change of leadership approaches there is very little OVCs are benefitting from, if anything at all. The contemporary leaders and their stakeholders bypass the traditional leaders and thereby cause conflicts that normally end up destroying the smooth operation of the projects. The caregivers, just like the community leaders, were asked on their views on the solution to the challenges and the popular view was the integration of traditional and contemporary leadership roles in OVC care and support. Most of the informants appreciate that there are significant roles that both the contemporary and traditional leaders can do in support of OVC separately, but they can do it better when there is harmony amongst the key stakeholders.

\section{DISCUSSION OF THE FINDINGS}

Different views of the traditional leaders, faith-based organisation representative, non-governmental organization representative, government line ministries representatives and caregivers on the roles of traditional leadership in OVC care and support in Zimbabwe were presented. The three most common views that emerged regarding impediments to the viability of traditional leadership in OVC care and support in Zimbabwe were disharmony between the traditional and contemporary leadership roles, lack of resources, and the key stakeholders' political differences. In view of the tensions between the leadership approaches, Ringson (2017) asserts that ideological conflicts between traditionalism and contemporary leadership within the tribal rural communities of Zimbabwe need to be addressed. These ideological conflicts are a reflection that traditional leadership is being consigned to the margins of history. Empirically, the findings have shown that there is disharmony between the traditional approach that is guided by the closed-system leadership approach and the open-system contemporary leadership approach. This view was validated by an informant who indicated that traditional leaders in Zimbabwe are operating on delegated authority from government in breach of their roles as stipulated in the Traditional Act of 2001 and enshrined in the new Constitution of Zimbabwe of 2013.

Whilst the contemporary leadership approach was supposed to have embraced the open-systems leadership (liberal) approach in its totality, it just took over from the traditional old ways of doing things and mixed them together with pseudo-democratic processes. This was evidently supported by the findings which testifies that the ruling party in Zimbabwe has been using an authoritarian approach in implementing its 
polices without involving the grassroots. The findings also showed that the ruling incumbent political party (Zanu-PF) manipulated traditional leadership styles and forced people to conform to their own leadership appointments. Machingura (2012) pointed out that traditional and religious songs which used to be sung for the traditional leaders at their traditional ritual ceremonies are now sung for political leaders, endorsing the heroic theories of leadership such as the great man theory, the contingency theory and other related theories which are of little significance in our modern societies. This was a direct characteristic of the traditional leadership style of the chiefs, headmen, the village heads and the spirit mediums manifesting in modern state structures, especially during Mugabe's leadership (Ndlovu-Gatsheni, 2015).

It was clear that the roles of traditional leadership in OVC care and support have been reduced to their being mere custodians of culture, traditional religions and traditions of the rural communities of Zimbabwe. The study also showed that the traditional leaders are being used as campaigning agencies by the ruling party, or rather, the political commissars of the ruling party. Simply put, traditional leaders are extensions of the incumbent government which has usurped their sacred authority in exchange for salaries and fringe benefits. Chigwata (2016) argues that this practice of paying remuneration to the traditional leaders was initiated during the colonial period, when chiefs, headmen and village heads received salaries from the government just like civil servants. Evidently, the aspect of remuneration shows that traditional leaders are now accountable to the government in contravention of the notion of parallel governance systems stipulated in the Traditional Act of 2001 and the Constitution of Zimbabwe of 2013. Thus, as indicated by some participants, corruption is no longer an issue linked to the government officials only, it has cascaded down to the traditional leaders. Those resources at their disposal which were meant to help the poor are manipulated for personal gain. Machingura (2012) argues that the kings and chiefs were valued and respected by their subjects based on their ability to feed them, dispense justice and ensure their wellbeing. This conceptualization of the chiefs was allegedly taken over by the current presidents and their cabinet ministers in their contemporary leadership styles, which reduced the chiefs to the level of ordinary citizens.

As much as the portfolios of the chiefs and kings were recognized based on their supernatural powers to communicate with the gods on behalf of their members, with their ability to feed the people, their execution of justice and ensure the general welfare of people, it implies that the politicians had ingeniously improvised ways to control them. The lack of resources of the chiefs implies their lack of power and the weakness of the traditional governance systems. A typical example of these methods was to distance them from resources, giving them gratuities and incapacitating them politically. The informants of this study indicated the failure of the strategies and the welfare programmes of the chiefs can also be associated with the lack of resources and political interference, among other factors. Empirically, the care-givers and traditional leaders indicated that community-based OVC coping strategies linked to traditional leaders are failing mainly because of lack of resources and political interference. This area of concern manifests itself in a number of ways: the poor working relationships between the traditional leaders and the incumbent government; poor working relationships with other stakeholders such as NGOs and FBOs based on beliefs, culture and working ethos; and the Zunde raMambo welfare model that was predominantly based on traditional structures being taken over by the government. The implication of interference by the government in the NGOs and FBOs compromises the services of the social development profession practitioners. This is because, whilst some social development practitioners come from the government, most the community development work, and OVC care and support in particular is spearheaded by the social practitioners from the NGOs and FBOs In Zimbabwe.

Similarly, whilst the extended family welfare model is still operational, it is overwhelmed by demands because of the poor economic situation in Zimbabwe, as well as the diluted status of the traditional governance systems. Regarding the relevance of traditional leadership and the king's granary welfare model, findings explained that whilst Zunde raMambo can be still relevant today because the traditional leaders' structures are still there in their communities, its essence has been distorted by modernity. This is where the maxim that 'Where two elephants fight, the grass suffers the most' comes into picture. The 
power struggle between the parallel systems disadvantages those at the grassroots levels and vulnerable people such as OVCs Chigwata (2016). Ringson (2017) asserts that traditional leaders are now directly embroiled in corruption and greed by amassing vast tracts of land and other resources for themselves at the expense of the disadvantaged in their communities.

In this regard, it was recently discovered that Mugabe owns more than 15 farms and most of his cabinet ministers own at least two farms each. In the process of taking that land, it was reported that Mugabe dispersed and left the poor and disadvantaged people homeless. This is a typical manifestation of the closed-systems approach where the leaders of the country are not held accountable for the injustices that they have committed. According to the Traditional Act of 2001, the land belongs to the state, but the traditional leaders own their tribal trust land, and farms which are corruptly owned by the government leave the local rural people without even land for grazing their livestock.

By implication, this means that traditional leaders are now being used as accomplices of corrupt politicians and simply rubber stamp the decisions of the political elites. It can be argued that the failure of the community-based OVC coping strategies and programmes can be attributed to the political oversight of the incumbent government in humanitarian work and relief services implemented with other stakeholders. Whilst lack of resources is a recurring theme from all the stakeholders, it can also be deduced that the political ideology of the government, that is the closed-system leadership approach, has deterred investors. At both household level and community level, the traditional leaders' responsibilities in Zimbabwe and Gutu District have been socio-economically and politically diluted so that they cannot independently execute their powers in important issues without consultation with government.

\section{CONCLUSION AND IMPLICATIONS FOR THE SOCIAL WORK PROFESSION}

The OVC challenges in the rural tribal communities of Zimbabwe demand a dynamic, creative, holistic and dialectical combination of focused and united stakeholders, namely government, traditional leadership and civil society. In view of the need for united stakeholders in OVC care and support, the social work profession needs to understand the dynamics of traditional leadership in OVC care and support within the rural communities. Thus, the contemporary and the traditional leadership approaches should be merged to produce a contextually-based united integrated model. Existing OVC programmes in Zimbabwe, although they are philanthropic in nature, should be co-ordinated like business systems with all that goes with the principles of good governance, inter alia, efficiency, effectiveness, economy, accountability and transparency. This has a strong bearing on the responsibilities, aims, strategies and envisaged outcomes if they are to have any purposeful existential impact on the OVC care and support systems. The challenge of mainstream OVC care and support strategies is that they are foreign to the Zimbabwean context and were transplanted from the West with few concessions to Zimbabwean culture, resulting in the impact being culturally alienating. This is the main challenge of taking the contemporary leadership approaches to the extreme in the rural tribal communities like the Gutu District of Zimbabwe.

The contemporary leadership approach has also influenced the social work profession curriculum to the extent that it has negated the indigenous cultural approaches entrenched in traditional leadership roles. The contemporary theories of the social work profession in the Zimbabwean training institutions must be largely directed towards understanding the traditional leadership approaches, especially for those who undertake their services within the rural communities. This will help to remove the friction and conflicts of interests between a contemporary social worker and the traditional caregivers and leaders within the rural communities. There is thus a need for a fresh approach that starts at the theoretical level and will address the gaps in traditional and contemporary leadership perspectives and develop a sound integrated approach. This theoretical engagement must start with the community development practitioners and social work professional practitioners. The practitioners should be engaged in such a way that they can be able to transform irrelevant traditional approaches and also blend the relevant traditional approaches with the contemporary approaches without meddling in the politics of the land. Whilst this is a big issue from the 
evidence of the findings for the social work and social development practitioners to interfere with the politics of the land, it is also their role to advocate for social justice within their jurisdiction. Thus, this can only be achieved through blending the social work training with the understanding of the leadership contestation between the traditional and contemporary approaches, which affects the livelihood of OVCs in Zimbabwe. Without such an approach, any potential solution to the OVC challenges will continue to fail and implementing it starts with leadership. In the theoretical literature review, it was conspicuous that traditionalism and modernism have relevant compatible elements that, when blended, will inform a new integrated model suitable for alleviating OVC challenges. This blended model builds on the strengths which mutually reinforce the closed and open systems leadership perspectives rather than merely depending on one. Based on the failure of traditional and contemporary coping strategies in isolation of each other, as established by the findings, this study suggests that such an integrated model could be well placed to address the identified OVC challenges and enhance the effectiveness of the social work profession within the rural communities of Zimbabwe.

\section{REFERENCES}

AYITTEY, G. 2006. Indigenous African institutions ( $2^{\text {nd }}$ ed). Airdsley: Transnational Publications.

AYITTEY, G. 1991. Indigenous African institutions. California: Transnational Publications.

BANANA, C. S. 1995. The church and the struggle for Zimbabwe: From the programme to combat racism to combat theology. Gweru: Mambo Press.

BLOOR, M, FRANKLAND, J., THOMAS, M., \& ROBSON, K 2001. Focus groups in social research. London: Sage Publishers.

BOURDILLION, M. 1990. Religion and society: A text for Africa. Gweru: Mambo Press.

BRAUN, V., \& CLARKE, V. 2006. “Using thematic analysis in psychology.” Qualitative Research in Psychology, 3:77-101.

BROODRYK, J. 2004. Ubuntu African life coping skills: Theory and practice (Paper Delivered at CCEAM Conference 12-17 October 2006), Lefkosia: Cyprus.

CHIGWATA, T. 2016. The role of traditional leadership in Zimbabwe: Are they still relevant, Journal of Law Democracy and Development, 7(20): 2-20.

CONSTITUTION OF ZIMBABWE. 2013. Abridged draft constitution of the Republic of Zimbabwe (Final draft 31 January 2013). Harare: Government Printers.

GELFAND, M. 1997. Ukama: Reflections on Shona and western cultures in Zimbabwe. Gweru: Mambo Press.

GERMANN, S.E. 2005. An exploratory study of quality of life and coping strategies of orphans living in child headed households in the high HIV/AIDS prevalent city of Bulawayo, Zimbabwe. University of South Africa, Pretoria. (PhD thesis)

GOVERNMENT OF ZIMBABWE. 2013. Zimbabwe agenda for sustainable socio-economic transformation (ZIMASSET 2013-2018). Harare: Government Printers.

GYEKYE, K. 1997. An essay on African philosophical thought: The Akan conceptual scheme. New York: Cambridge University Press.

HEWLET, L. 2013. Decontextualizing knowledge in the curriculum in public management. Johannesburg: University of Witwatersrand. (PhD thesis)

HODGSON, D. 2009. The Rise and demise of children's international rights. Australia: University of Western Australia.

LETSEKA, M, M. 2012. An analysis of undergraduate philosophy of education students' perception of African philosophy. Pretoria: University of South Africa. (PhD thesis) 
LUMBI, C.P. 2007. The emotional well-being, social-being, social adjustment and coping strategies of orphans, and vulnerable children affected by HIV/AIDS. Burg: Johannesburg: University of the Witwatersrand. (Masters dissertation)

LINCOLN, Y. \& CUBA, E. 1985. Naturalistic inquiry. Beverly Hills: Sage Publishers.

MACHINGURA, F. 2012. The messianic feeding of the masses: An analysis of John 6 in the context of cessianic leadership in post-colonial Zimbabwe. Nürnberg: University of Bamberg Press. $(\mathrm{PhD}$ thesis)

MARARIKE, C. 2004. Revival of indigenous food security strategies at village levels: The Human Factor Implications. Zambezia, XXVIII (i): 53-65.

MARARIKE, C. 2014. Land: An empowerment asset for Africa: The human factor experience. Harare: University of Zimbabwe.

MATSHABAPHALA, J. 2017. Traditional leadership and a simpler way to accountability in local government, The $2^{\text {nd }}$ annual international conference on public administration and development alternatives, 26-28 July 2017. Gaborone: Tlotlo Hotel.

MASUKA, T, BANDA, G.R., MABVURUR, V. \& FRANK, R. 2012. Preserving the future: Social protection programmes for orphans and vulnerable children (OVC) in Zimbabwe. International Journal of Humanities and Social Sciences, 2 (12): 5 -66.

MAX-NEEF, M. A. 1993. Development and human needs. In P. Ekins, \& M.A. Max-Neef (eds.). Real life economics: Understanding wealth creation 99-213. London: Routledge.

MERRIAM, S. 2009. Qualitative research: A guide to design and implementation. San Francisco: Jossey-Bass-A Willy Imprint Publishers.

MOSANA, M. S. 2002. Effectivity and productivity in education: An ubuntu perspective. Potchefstroom: Potchefstroom University. (Masters dissertation)

MUGUMBATE, J., \& CHERENI, 2019. Using African ubuntu theory in social work with children in Zimbabwe. Southern African Journal of Social Work, 9 (1): 27-34.

NDLOVU-GATSHENI, S. 2015. Mugabeism? History, politics, and power in Zimbabwe, New York: Palgrave MacMillan.

RINGSON, J. 2017. Zunde raMambo as a traditional coping mechanism for the care of orphans and vulnerable children: Evidence from Gutu District, Zimbabwe, African Journal of Social Work, 7(2): $52-59$.

RINGSON J. 2019. The impact of inheritance experiences in orphans and vulnerable children support in Zimbabwe: A caregivers' perspective. Child \& Family Social Work: 1-9. [Online] Available: https://doi.org/10.1111/cfs.12630. [Accessed: 27/02/2019].

RINGSON, J. 2019. The impact of child rights cultural contestation in and vulnerable children support in Zimbabwe. Child Abuse Research Journal, 20 (1): 51-61.

ROBY, J. 2011. Children in informal alternative care. New York: UNICEF.

SHANALINGIGWA, O.A. 2009. Understanding social and cultural differences in perceiving child maltreatment. Minnesota: University of Minnesota. (PhD dissertation)

TEFFO, J. 1994. Towards conceptualization of ubuntu. Pretoria: Ubuntu School of Philosophy.

WORLD BANK. 2000. Governance and development. Washington DC: World Bank. 